\title{
Comparative study of obstetric outcome in overweight and obese pregnant women
}

\author{
Permanand Keshavlal Shah, Hemangi Kashinath Chaudhari*, Surbhi Garg
}

Department of Obstetrics and Gynecology, Seth GS Medical College and KEM Hospital, Mumbai, Maharashtra, India

Received: 22 May 2018

Accepted: 26 June 2018

\section{*Correspondence:}

Dr. Hemangi Kashinath Chaudhari,

E-mail: hemangichaudharik@gmail.com

Copyright: () the author(s), publisher and licensee Medip Academy. This is an open-access article distributed under the terms of the Creative Commons Attribution Non-Commercial License, which permits unrestricted non-commercial use, distribution, and reproduction in any medium, provided the original work is properly cited.

\begin{abstract}
Background: The World Health Organization has described obesity as one of today's most neglected public health problems, affecting every region of the globe. The objective of the present study was to compare obstetric outcome in overweight and obese pregnant women.

Methods: A prospective observational study was conducted in obstetrics and gynecology department in KEM hospital, Mumbai between 2014- 2015 to study the effects of maternal BMI on maternal and perinatal outcome and to compare the obstetric outcome (maternal and perinatal) between overweight and obese mother. All antenatal patients fulfilling inclusion criteria were divided in two groups, overweight and obese based on BMI $<30 \mathrm{~kg} / \mathrm{m}^{2}$ and $>30$ $\mathrm{kg} / \mathrm{m}^{2}$ respectively. Distribution of maternal risk factors like gestational hypertension and preeclampsia, gestational diabetes mellitus, unfavourable obstetric history specially in previous pregnancy like miscarriages, and instances of fetal demise, history of previous caesarean section and perinatal outcome were studied.

Results: Maternal personal characteristics like increased age and low education level were related to high BMI and antenatal complications like gestational diabetes, gestational hypertension, malpresentation, preterm labor, incidences of assisted vaginal delivery and rate of caesarean section and perinatal complications were higher in obese group.

Conclusions: The study concluded that obesity has adverse effects on pregnancy outcome on both mothers and their infants. Increased age and low education status in relation with high BMI showed adverse pregnancy outcome. Stronger association seen between family history of obesity and diabetes and increased BMI. This study revealed that GDM, Gestational hypertension and malpresentations found commoner in obese mothers than overweight mothers.
\end{abstract}

Keywords: BMI, Maternal risk, Obese and overweight mothers

\section{INTRODUCTION}

The World Health Organization has described obesity as one of today's most neglected public health problems, affecting every region of the globe. ${ }^{1}$ WHO describes obesity as - one of the most blatantly visible, yet most neglected, public health issue and as per WHO it is a "Killer Disease" at par with HIV and Malnutrition. Even in India significant proportion of overweight and obese coexist with the undernourished. Lifestyle modifications over the years have led to a more sedentary lifestyle. This is of global concern as excess bodyweight is now the sixth important risk factor contributing to disease worldwide and increased level of obesity may result in a decline in life expectancy in the future. ${ }^{2,3}$

The WHO "World Report" affirms that 1200 million people throughout the world have over weight and obesity problems and epidemiological studies show that, $22 \%$ of adult population are obese4. National Family Health Survey (NHFS-3) 2005-06 of India defines obesity as body mass index above $30.0 \mathrm{~kg} / \mathrm{m}^{2} .5$ It also 
states that the percentage of married women aged between 15-49, who are over-weight or obese increased from $11 \%$ in NHFS -2 (2003-04) to $15 \%$ in NHFS-3. The WHO also recognizes obesity as a pandemic issue, with higher prevalence in females than males. ${ }^{6}$ As a result many pregnant women are seen with higher body mass index (BMI).

Pregnancy with obesity is considered as high risk and it causes substantial feto-maternal morbidity and mortality. Complications like pregnancy induced hypertension (PIH), chronic hypertension, pre-eclampsia, gestational diabetes mellitus (GDM), overt diabetes, thromboembolic phenomena and infection morbidities etc. are increased in obese pregnant women. ${ }^{6-9}$ The Confidential Enquiry into Maternal and Child Health (CEMACH), 2004 had reported that $35 \%$ of all maternal deaths in 2000-2002 were observed in obese women $\left(\mathrm{BMI} \geq 30 \mathrm{~kg} / \mathrm{m}^{2}\right){ }^{10}$ Offspring of these mothers also have increased risk of macrosomia, shoulder dystocia, preterm deliveries, congenital malformations and can lead to late intrauterine fetal deaths(IUFD). ${ }^{6,8,11,12}$

\section{METHODS}

All antenatal women attending obstetric outpatient department who fulfilled inclusion criteria were asked for a questionnaire including age, parity, weight (either Prepregnancy weight or the earliest pregnancy weight up to 20 weeks), height, BMI (Weight in $\mathrm{kg} /$ Height in meter ${ }^{2}$ ) and gestational age, past medical and surgical history, past obstetric history was followed till term to include complication and maternal and neonatal outcome of current pregnancy. BMI was calculated by using Quetlet index.

\section{Inclusion criteria}

- Primigravida or Multigravida with singleton pregnancy with BMI of 25 and above.

\section{Exclusion criteria}

- Multifetal gestation

- Eclampsia

- Known case of diabetes mellitus

- Hypertension

- Coronary heart disease

An observational study was conducted in two comparative groups based on distribution of maternal risk factors like gestational hypertension and preeclampsia, gestational diabetes mellitus, unfavourable obstetric history specially in previous pregnancy like miscarriages, and instances of fetal demise, history of previous caesarean section, abnormal fetal growth development, abnormal presentation, placenta previa, preterm labour, prematurity, post-maturity and mode of delivery. Intrapartum and postpartum complication like spontaneous or induced labour, non-progress of labour, failure of induction, fetal distress, shoulder dystocia, postpartum haemorrhage, birth injuries. Perinatal outcome like large for gestational age, congenital abnormalities, Apgar score, admission to NICU, still birth were studied.

\section{RESULTS}

60 women were included in the study, 30 in each group. This study showed different variation of demographic, obstetric history, anthropometric characteristic, major maternal and perinatal outcome among overweight and obese pregnant females.

In present study among both overweight and obese mother, 32 mothers $(53.33 \%)$ were age of $>30$ years and $46.70 \%$ mothers had only primary education.

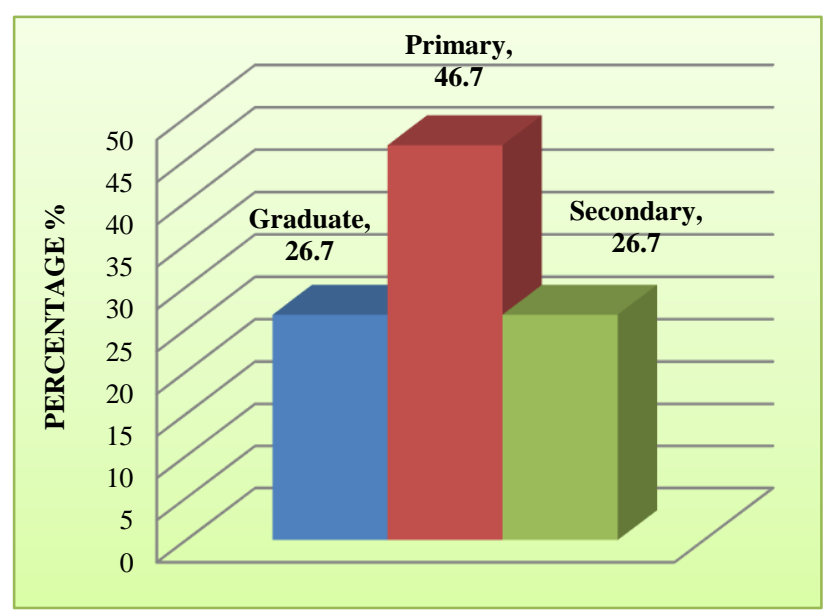

Figure 1: Education status in studied group.

$53.22 \%$ mothers had positive family history of obesity, diabetes and hypertension. $54.80 \%$ obese and $45.20 \%$ overweight mothers showed complications in previous pregnancy like bad obstetric history, intrauterine fetal death, previous caesarean section, malformed baby, macrosomia, though the $\mathrm{p}$ - value showed insignificant difference in two groups.

In the present pregnancy $52.7 \%$ mothers in obese group and $47.3 \%$ overweight mothers had antepartum complications like pre-eclampsia complicated $19.23 \%$ pregnancies in BMI $<30$ and $24.1 \%$ pregnancies in BMI $>30$. GDM complicated $3.85 \%$ overweight pregnancy and $31.03 \%$ obese pregnancies.

Abnormal presentations and anaemia were commoner in overweight pregnancies (19.23\%) while in obese pregnancies it was $13.79 \%$. IUGR, hypothyroidism was commoner in overweight pregnancy while incidences of IUFD were higher in obese pregnancy.

Preterm labor pains were commoner in the BMI $>30$ than in BMI <30 while postdatism was more common in overweight pregnancy than obese pregnancy. 


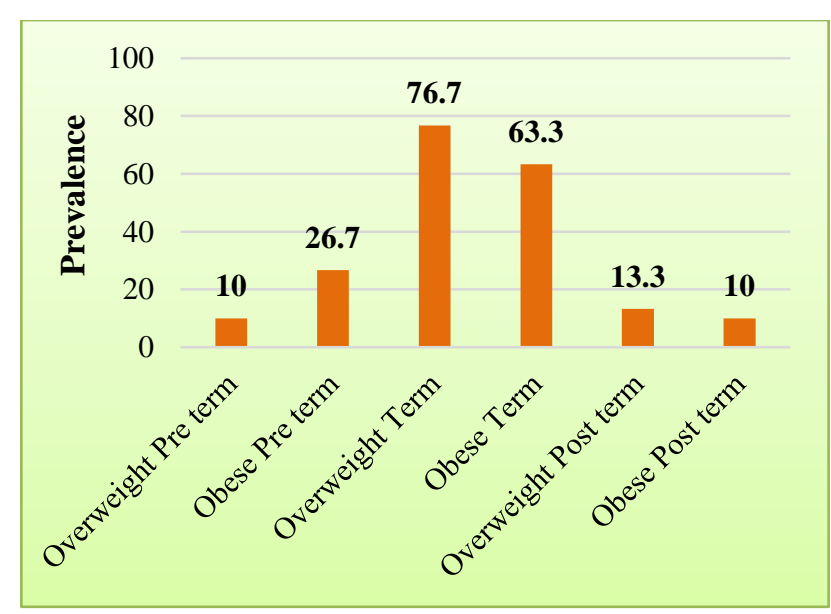

Figure 2: Comparative presentation of pre-term, term and post-term pregnancy in both groups.

Mean gestational age was 38.14 in overweight and 36.93 in obese category with $\mathrm{p}$ value of 0.185 making it statistically insignificant.

$63.3 \%$ overweight and $70 \%$ obese mothers had induced labor and caesarean sections were commoner in obese group than overweight group.

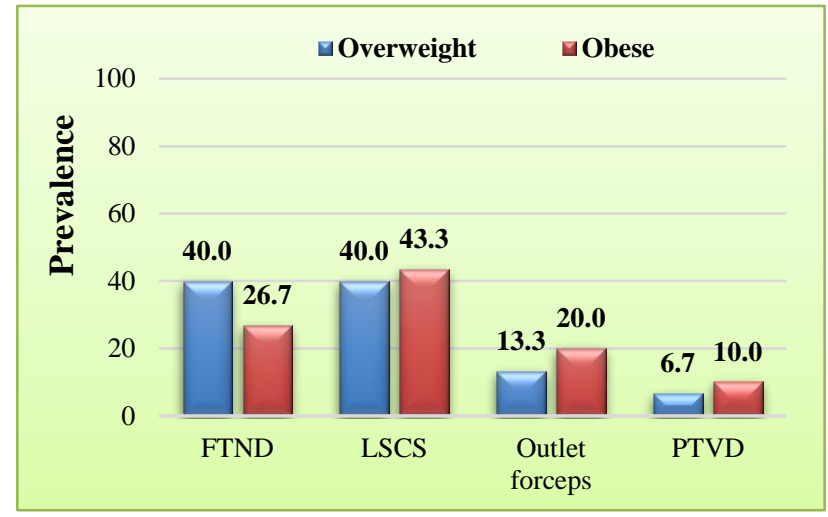

Figure 3: Modes of delivery in both groups.

$86.66 \%$ obese and $43.3 \%$ overweight mothers had intrapartum complications like prolonged labor, fetal distress, meconium stained amniotic fluid, obstructed labor and birth injuries. $71.4 \%$ obese mothers and $50 \%$ overweight mothers had intraoperative complications in form of difficult spinal needle insertion, difficulty in placement of endotracheal tube, excess blood loss and prolonged surgery. One patient had uterine rupture. Difficulty in spinal needle insertion and need of blood transfusion was most common complications in obese group and increased duration of surgery was commonest complication in overweight mothers.

Obese mothers had slightly more difficulty in initiation of breast feeding than in overweight mothers. Rate of wound infection and wound gape were equal in both overweight and obese mothers.
Table 1: Rate of wound infection in both groups.

\begin{tabular}{|llllll|}
\hline & & Overweight & Obese & \\
& & Count & $\begin{array}{l}\text { Column } \\
\text { N \% }\end{array}$ & Count & $\begin{array}{l}\text { Column } \\
\text { N\% }\end{array}$ \\
\hline $\begin{array}{l}\text { Wound } \\
\text { infection }\end{array}$ & Yes & 7 & 23.3 & 7 & 23.3 \\
\cline { 2 - 6 } $\begin{array}{l}\text { and } \\
\begin{array}{l}\text { wound } \\
\text { gape }\end{array}\end{array}$ & Total & 23 & 76.7 & 23 & 76.7 \\
\hline
\end{tabular}

About $91.66 \%$ of the participant mothers delivered live birth infant and $8.33 \%$ was neonatal death.

The mean infant birth weight was $2.668 \mathrm{~kg}$ and SD \pm 0.697 , the minimum infant birth weight was $640 \mathrm{gm}$ and the maximum was $3.670 \mathrm{~kg}$. About $68.33 \%$ baby have normal birth weight $(2500 \mathrm{~g}-4000 \mathrm{gm})$, no baby has large birth weight $(>4000 \mathrm{gm})$ and $31.66 \%$ have low birth weight $(<2500 \mathrm{gm})$. Obese mothers have higher rate of congenital malformations $(20 \%)$ compare to overweight mothers $(10 \%)$.

NICU admission-neonates of obese mothers had higher rate of intensive care admission $(46.7 \%)$ rather than neonates of overweight mothers $(16.7 \%)$. It was showing statistically significant difference with $\mathrm{p}$ value of 0.012 . Main indication of NICU admission was infants of diabetic mother and congenitally malformed baby.

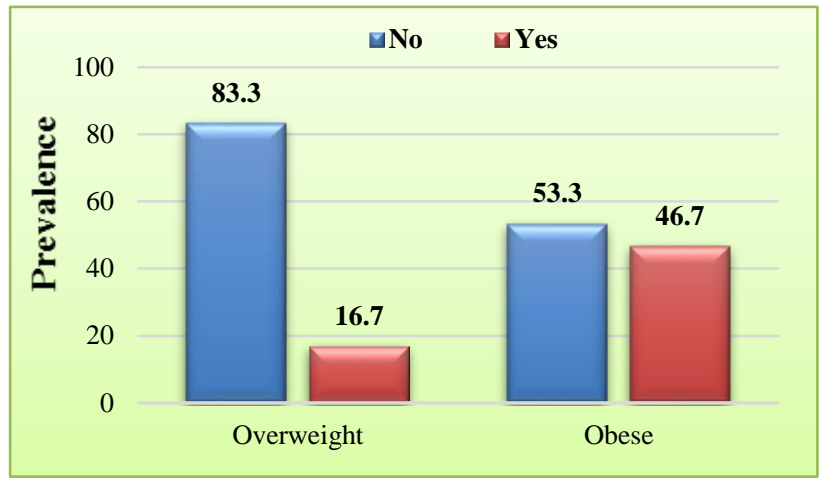

Figure 4: NICU admission in relation to BMI.

\section{DISCUSSION}

Preeclampsia leads to increased perinatal morbidity and mortality due to associated IUGR and fetal hypoxia. This study was conducted to compare obstetric outcome between overweight and obese pregnancies and the relationship between maternal obesity and pregnancy outcome. Waldenstrom et al compared the association of maternal age with BMI with pregnancy outcome. In our study $53.33 \%$ women had BMI $>25 \mathrm{~kg} / \mathrm{m}^{2}$, were $>30$ years old. ${ }^{13}$ In present study maximum number of overweight and obese mothers were having low education level. In studied participants, $53.33 \%$ overweight mothers and $64.71 \%$ obese mothers gave family history of obesity. Maximum patients were 
showing family history of obesity followed by diabetes mellitus and hypertension. Kulie, MD et al in an evidence-based review followed 84,000 female nurses for 16 years and found that being overweight or obese was the single most important predictor of diabetes mellitus. ${ }^{14}$

In present study there were high prevalence of previous LSCS and intra uterine fetal death in overweight pregnancy while history of pre-eclampsia, abortion, macrosomia and malformed baby were higher in obese mothers.

\section{Concurrent disorders during pregnancy}

\section{Gestational diabetes mellitus}

In this study, GDM complicated $3.85 \%$ overweight pregnancy while $31.03 \%$ obese pregnancies complicated by GDM. Present study shows similar results to the study done by Ogowski et al in which 1121 females showed significant relationships between pregravid BMI and GDM $\left(22.85 \mathrm{~kg} / \mathrm{m}^{2}\right.$ was taken as cut value $) .{ }^{15}$ In present study pre-eclampsia complicated $19.23 \%$ pregnancies in $\mathrm{BMI}<30$ and $24.1 \%$ pregnancies in $\mathrm{BMI}>30$.

\section{Gestational hypertension and preeclampsia}

In present study pre-eclampsia complicated $19.23 \%$ pregnancies in $\mathrm{BMI}<30$ and $24.1 \%$ pregnancies in $\mathrm{BMI}$ $>30$.

A cross-sectional study conducted in 244 women of which $8.6 \%$ were hypertensive and $25 \%$ were prehypertensive. Overweight and obesity $(p=0.02)$ and family history $(\mathrm{p}=0.001)$ were having significant association with presence of hypertension.

Variations in the prevalence of PIH among different studies could be attributed to misinterpretation of the blood pressure measurement in antenatal visit due to use of inappropriate cuff and subjective difference.

Malpresentation in present study $16.36 \%$ mothers showed abnormal presentation whereas BMI >30 shows higher prevalence $(19.23 \%)$ than BMI <30 (13.79\%). Present study results were similar to those of Sheiner $E$ et al reported malpresentations at a significantly higher rate in the obese mothers $(\mathrm{P}<0.001){ }^{16}$

Gestational age of termination- Preterm labor pains were commoner in the obese mothers than in overweight mothers. Overall postdatism found more than preterm labor.

Sharashova et al studied 29,707 pregnant mothers and found associations between maternal BMI and PTB and found underweight, overweight and obese women had, on average, $25 \%, 10 \%$ and $31 \%$ higher risk of PTB compared to the normal weight group, although the effect of overweight was not significant. ${ }^{17}$ Merging overweight and obese women into one group resulted in an OR of 1.16 (95\% CI: $1.03-1)$.

\section{Type of labor}

In this study in $63.3 \%$ overweight mothers and $70 \%$ obese mothers required induction of labor which is supported by Arrowsmith $\mathrm{S}$ et al who studied a total of 29, 224 women with singleton pregnancies between 2004 and 2008 of whom 3076 had a prolonged pregnancy (defined as $\geq 290$ days or $41(+3)$ weeks of gestation) and received induction of labor (IOL). ${ }^{18}$ Present data suggested that IOL for prolonged pregnancy in obese women is a reasonable and safe management.

In this study $86.66 \%$ of obese and $43.33 \%$ of overweight mothers showed different complication in form of fetal distress, failure of induction, birth injury and shoulder dystocia. Bianco et al found increased incidence of fetal distress $(12.4 \%)$ in the obese as compared to non-obese $(8.7 \%){ }^{19}$

\section{Mode of delivery and related complication}

In present study overall in both groups vaginal delivery was $45 \%$, rate of LSCS was $41 \%$ and instrumental delivery conducted in $16 \%$ cases. Rate of LSCS was approximately same in both group.

\section{Intraoperative complications}

$71.4 \%$ obese patients and 50\% overweight had intraoperative complications in form of difficult spinal needle insertion, difficulty in placement of endotracheal tube, excess blood loss and prolonged surgery A metaanalysis of 33 cohort studies showed that the OR for caesarean section (either elective or emergency) was 1.46 (95\% CI 1.34-1.60) and 2.05 (95\% CI 1.86-2.27) respectively among women defined as overweight and obese in individual studies, compared to women with a normal weight. ${ }^{20}$

Post-partum haemorrhage was same in both groups. Arrowsmith $\mathrm{S}$ et al found in a retrospective cohort study that there was a non-significant trend for estimated blood loss $>1000 \mathrm{ml}$ in obese women compared with women of normal weight. $^{21}$ In my study $71 \%$ obese patients underwent different anaesthesia related complications compare to overweight pregnancy which were $50 \%$. A number of sources indicate that women with a BMI greater than 35 are at an elevated risk of anaesthesiarelated complications (Catalano and Ehrenberg, Fitzsimons and Modder). ${ }^{22}$

In present study both overweight and obese mothers had equal rate of wound infections and wound gape while need of higher antibiotics was just double in obese group compare to overweight. This shows obesity as an independent risk factor for infection. 
Women with high BMIs are more likely to endure increased blood loss, operation times, endometritis, vertical skin incisions, and postoperative wound infections.

\section{Difficulty in initiation of breast feeding}

Maternal obesity is associated with reduced breastfeeding rates, both in terms of breastfeeding initiation and duration. ${ }^{23,24}$ This is likely to be multifactorial in origin; women's perception of breastfeeding; difficulty with correct positioning of the baby; and the possibility of an impaired prolactin response to suckling. Evidence derived from randomised controlled trials in the general maternity population shows that breastfeeding education and support is associated with higher breast feeding initiation rates and, in some instances, longer durations of breastfeeding.

In present study both overweight and obese mothers had equal rate of wound infections and wound gape while need of higher antibiotics was just double in obese group compare to overweight. This shows obesity as an independent risk factor for infection.

Women with high BMIs are more likely to endure increased blood loss, operation times, endometritis, vertical skin incisions, and postoperative wound infections.

\section{Neonatal outcome}

Neonates of obese mothers had higher rate of intensive care admission (46.7\%) compared to neonates of overweight mothers $(16.7 \%)$. It was showing statistically significant difference with $\mathrm{p}$ value of 0.012. Main indication of NICU admission were mainly infants of diabetic mother and congenitally malformed babies. the current study shows that $41.66 \%$ of them suffered at least one of unfavourable outcome such as stillbirth, prematurity, post maturity congenital anomaly, birth trauma, congenital heart disease cyanosis, jaundice, or LBW. The risk of congenital malformations in obese women (BMI $\geq 30$ ) was higher than that in overweight women. Also, the study reveals that the rate of delivery of macrosomic infants is increased by increasing maternal BMI, $13.9 \%, 21.9 \%, 25 \%$ for obesity classes 1, 2, 3 respectively. This is supported by Marshall et al, who stated that super obese women were significantly more likely than obese women to have macrosomia. ${ }^{25}$

\section{CONCLUSION}

The study concluded that obesity has adverse effects on pregnancy outcome on both mothers and their infants. Increased age and low education status in relation with high BMI showed adverse pregnancy outcome. Stronger association seen between family history of obesity and diabetes and increased BMI. This study revealed that GDM, Gestational hypertension and malpresentations found commoner in obese mothers than overweight mothers.

Both the groups of BMI required induction of labor because of prolonged labor. Caesarean section (40\%) was as high as normal vaginal delivery in both groups. Preterm birth was commoner than postdatism. Congenital malformation and were common in both groups of BMI. There was Increased need of intensive care in neonates, unfavourable outcome such as still birth, prematurity, post maturity, birth trauma.

Funding: No funding sources

Conflict of interest: None declared

Ethical approval: The study was approved by the Institutional Ethics Committee

\section{REFERENCES}

1. Pednekar MS, Hakama M, Hebert JR, Gupta PC. Association of body mass index with all-cause and cause-specific mortality: findings from a prospective cohort study in Mumbai (Bombay), India. Int $\mathbf{J}$ Epidemiol. 2008;37(3):524-35.

2. James WP. WHO recognition of the global obesity epidemic. Int J Obes (Lond). 2008;32 Suppl 7:S1206.

3. Haslam DW, James WP. Obesity. Lancet. 2005; 366(9492):1197-209.

4. Marshall NE, Guild C, Cheng YW, Caughey AB, Halloran DR. Maternal super obesity and perinatal outcomes. Am J Obstetr Gynecol. 2012;206(5):417e1.

5. National Family Health Survey (NHFS-3), 2005-06. Adult Nutrition, India.

6. Satpathy KH, Fleming A, Frey D, Barssom M, Satpathy C, Fossen K. Maternal obesity and pregnancy. Postgraduate Med. 2008;120: E01-09.

7. Heselhurst N, Lang B, Mannion K, Porch J, Rankin $\mathrm{J}$, Summerbell C, et al. Maternal obesity and pregnancy outcome: a scoping study. Nepho. 2006:22.

8. Andreasen KR, Andresen ML, Schantz AL. Obesity and pregnancy. Acta Obstet Gynecol Scand. 2005;83(11):1022-9.

9. Grossetti E, Beucher G, Regeasse A, Lamendour N, Herlicoviez M, Dreyfus M. Obstetrical complications of morbid obesity. J Gynecol Obstetr Reprod Biol. 2004;33(8):739-44.

10. Mandal D, Mandal S, Rakshit A, Dey RP, Biswas SC, Banerjee A. Maternal obesity and pregnancy outcome: a prospective analysis. J Assoc Phys India. 2011;59

11. Roman H, Robillard PY, Hulsey TC, Laffitte A, Kouteich K, Marpeau L, et al. Obstetrical and neonatal outcomes in obese women. West Indian Med J. 2007;56(5):421-6.

12. Barclay L, Lie D, et al. Offsprings of obese mothers may have increased risk of certain birth defects. Arch Pediatr Adolsc Med. 2007;161:745-50. 
13. Waldenström U, Aasheim V, Nilsen AB, Rasmussen S, Pettersson HJ, Schytt E. Adverse pregnancy outcomes related to advanced maternal age compared with smoking and being overweight. Obstet Gynecol. 2014 Jan;123(1):104-1.

14. Maggio CA, Pi-Sunyer FX. Obesity and type 2 diabetes. Endocrinol Metab Clin N Am. 2003;32(4): 805-22.

15. Ogonowski J, Miazgowski T, Kuczyńska M, Krzyżanowska-Świniarska B, Celewicz Z. Pregravid body mass index as a predictor of gestational diabetes mellitus. Diabetic Medi. 2009;26(4):334-8.

16. Sheiner E, Levy A, Menes TS, Silverberg D, Katz M, Mazor M. Maternal obesity as an independent risk factor for caesarean delivery. Paediatr Perinat Epidemiol. 2004;18(3):196-201.

17. Sharashova EE, Anda EE, Grjibovski AM. Early pregnancy body mass index and spontaneous preterm birth in Northwest Russia: a registry-based study. BMC Preg Childbirth 2014;14(1):303.

18. Arrowsmith S, Wray S, Quenby S. Maternal obesity and labour complications following induction of labour in prolonged pregnancy. BJOG: Int J Obstetr Gynaecol. 2011;118(5):578-88.

19. Bianco AT, Smilen SW, Davis Y, Lopez S, Lapinski R, Lockwood CJ. Pregnancy outcome and weight gain recommendations for the morbidly obese woman. Obstet Gynecol. 1998;91(1):97-102.
20. Chu SY, Kim SY, Schmid CH, Dietz PM, Callaghan WM, Lau J, et al. Maternal obesity and risk of cesarean delivery: a meta-analysis. Obesity Reviews. 2007;8(5):385-94.

21. Arrowsmith S, Wray S, Quenby S. Maternal obesity and labour complications following induction of labour in prolonged pregnancy. BJOG: Int J Obstetr Gynaecol. 2011;118(5):578-88.

22. Catalano PA, Ehrenberg HM. The short-and longterm implications of maternal obesity on the mother and her offspring. BJOG: Int J Obstetr Gynaecol. 2006;113(10):1126-33.

23. Vaidya AD. The formidable challenge of underweight, overweight and obese children in India. J Obesity Metab Res. 2014;1(1):4.

24. Marshall NE, Guild C, Cheng YW, Caughey AB, Halloran DR. Maternal superobesity and perinatal outcomes. Am J Obstet Gynecol. 2012;206(5):417.

25. Marshall NE, Guild C, Cheng YW, Caughey AB, Halloran DR. Maternal super-obesity and perinatal outcomes. Acta Obstet Gynecol Scand. 2010 Jul;89(7):924-30.

Cite this article as: Shah PK, Chaudhari HK, Garg S. Comparative study of obstetric outcome in overweight and obese pregnant women. Int J Reprod Contracept Obstet Gynecol 2018;7:3199-204. 